\title{
Importance of Age for 3-Year Continuous Behavioral Obesity Treatment Success and Dropout Rate
}

\author{
Pernilla Danielsson ${ }^{a} \quad$ Viktoria Svensson ${ }^{a}$ Jan Kowalski ${ }^{a} \quad$ Gisela Nyberg ${ }^{a}$ \\ Örjan Ekblom ${ }^{\mathrm{a}}$ b Claude Marcus $^{\mathrm{a}}$ \\ aDivision of Pediatrics, Department of Clinical Science, Intervention and Technology \\ (CLINTEC), Karolinska Institutet, National Childhood Obesity Center, Children's Hospital, \\ Karolinska University Hospital, ${ }^{b}$ Astrand Laboratory of Work Physiology, the Swedish School \\ of Sport and Health Sciences, Stockholm, Sweden
}

\author{
Key Words \\ Adolescent $\cdot$ Behavioral interventions $\cdot$ Childhood obesity $\cdot$ Lost to follow-up
}

\begin{abstract}
Objective: To assess whether first year weight loss, age, and socioeconomic background correlate with the success rate of continuous long-term behavioral obesity treatment. Methods: In a 3-year longitudinal study, obese children $(n=684)$ were divided into three groups based on age at the start of treatment, age 6-9 years, 10-13 years, and 14-16 years. Results: The mean BMI standard deviation score (BMI-SDS) decline was age-dependent ( $p=0.001$ ), independently of adjustment for missing data: -1.8 BMI-SDS units in the youngest, -1.3 in the middle age group, and -0.5 in the oldest age group. SES and parental BMI status did not affect the results. $30 \%$ of the adolescents remained in treatment at year 3 . There was only a weak correlation between BMI-SDS change after 1 and 3 years: $r=0.51(p<0.001)$. Among children with no BMI-SDS reduction during year $1(n=46), 40 \%$ had a clinically significantly reduced BMI-SDS after year 3. Conclusion: Behavioral treatment should be initiated at an early age to increase the chance for good results. Childhood obesity treatment should be continued for at least 3 years, regardless of the initial change in BMI-SDS.
\end{abstract}

Copyright $\odot 2012$ S. Karger GmbH, Freiburg

\section{Introduction}

There is general agreement that behavioral interventions constitute the cornerstone of childhood obesity treatment. There are many studies showing effects of short-term interventions, and follow-up studies have also indicated that some effects remain over a longer 
time period [1-4]. However, the importance of such treatment prerequisites like age at onset of treatment and hereditary factors has not been studied sufficiently. Furthermore, low socioeconomic status (SES) is observed more frequently in families with obese children [5], but it is unclear to what extent such factors affects the treatment outcome.

The large number of patients lost to follow-up during treatment is another well-known problem. Dropout rates of 30-40\% after 1 year are not uncommon [1], and even larger numbers up to $92 \%$ are found in long-term follow-up studies of 2-5 years $[3,4,6]$.

In adults SES seems to be of great importance for the risk of treatment dropout $[7,8]$. However, in younger patients, factors of importance for the dropout rate are basically unknown. A few earlier studies have investigated potential correlates to dropout in pediatric obesity and reported conflicting results [9-12].

The general aim of this study was to evaluate whether or not demographic and other patient-related factors correlated with the efficacy of long-term behavioral obesity treatment. The primary aim was to study whether age at the onset of treatment was of importance. Secondary aims were to study if socioeconomic factors, parental obesity, or age at obesity onset were correlated with change in BMI standard deviation score (BMI-SDS) during treatment and to what extent initial weight loss was correlated with the long-term success rate. We also studied what factors were correlated with subjects being lost to followup.

\section{Material and Methods}

\section{Treatment Modalities}

The National Childhood Obesity Center, Stockholm, is a referral center for children with severe obesity, the aim of which is to evaluate obesity treatment [13-15]. All children and their parents have agreed to continuous treatment for 5 years. A primary goal is to help families to understand the severity of the disease and the need for lifelong treatment. The objective of the behavioral treatment follows widely accepted guidelines [16-19]. The aim is to help patients to adopt healthier eating habits, to become more physically active, and to reduce time spent in sedentary activities. Changes are encouraged to be made stepwise, based on present behaviors. The treatments were provided individually and in groups. The overruling principle was that the treatment should be intensified if it failed. This means that if the results were poor (weight gain), more frequent visits were prescribed. Therefore, the frequency of weight controls varied from weekly to once a year. When patients did not apply for follow-up visits, the family was contacted immediately, first by proposing a new visit and after that by telephone calls and by letters to the caregiver. The whole treatment was free of charge for the families.

Patients

This is a longitudinal study in patients aged 6-16 years who had been referred to and accepted for treatment at the National Childhood Obesity Center, Stockholm, between January 1998 and December 2004 ( $\mathrm{n}=684)$. All included patients were obese according to the criteria suggested by Cole et al. [20] and had made at least one visit to the Center. At the time of evaluation, all included children had had the opportunity for a 3-year treatment period. Follow-up was terminated after 3 years of treatment or at the time of loss to follow-up, whichever came first. Patients undergoing other treatments than behavioral treatment or patients with other obesity-related diagnoses, such as syndromes, surgery within the central nervous system and mental and psychological disorders ( $\mathrm{n}=129)$, were excluded. After exclusions, 555 children remained in the study.

Data were extracted from the National Health Care Quality Register for Childhood Obesity (BORIS), which is supervised by the National Board of Health and Welfare in Sweden. The study database includes data from the first visit to the National Childhood Obesity Center and comprises background and demographic characteristics, i.e., gender, pubertal status, age at onset of obesity, parental weight status, SES (parental occupation) and BMI-SDS [21]. At all visits trained nurses assessed height (Ulmer stadiometer, Ulm, Germany) and body mass (Vetek TI-1200; Väddö, Sweden) with children wearing underwear and a 
lightweight shirt. Pubertal status according to Tanner was assessed by a pediatrician. The study was reviewed by the Ethics Committee of Karolinska Institutet, and the parents gave their oral informed consent for the registration of clinical data.

\section{Method}

The degree of obesity was classified using the BMI-SDS. [21]. The BMI-SDS was calculated in the BORIS database using weight, height, age, and gender. The subjects were divided into three age groups, defined by age at the start of behavioral treatment. The age brackets were 6-9 (prepubertal), 10-13 (pubertal), and 14-16 (late/post-pubertal) years. Age at onset of obesity was derived from growth charts as the age at which the BMI exceeded iso-BMI 30, i.e., the BMI that forecasts an adult BMI of over 30 [20]. It was possible to define age at onset of obesity in $80 \%$ of subjects.

Parental BMI data in the BORIS database were based on the weight and height data reported by the parents at the first clinical visit. The parents were classified with regard to overweight and obesity according to the international standards: normal weight (BMI 18-24.9 kg/m²), overweight (BMI 25-29.9 $\mathrm{kg} / \mathrm{m}^{2}$ ), or obese $\left(\mathrm{BMI}=30 \mathrm{~kg} / \mathrm{m}^{2}\right)[22]$.

SES was defined in terms of parental occupation/education. This was coded, based on official Swedish socioeconomic categories (SEI) and the Swedish Standard Classification of Occupations (SSYK) provided by Statistics Sweden (SCB), into three categories: i) at least one parent with an academic degree, ii) at least one parent with a post upper secondary school education, and iii) others (unemployed, early/disability retired, long-term sick-listed, students, housewives).

Most of the included patients received more than one type of behavioral treatment. We have not been able to demonstrate that one type of behavioral intervention has been more successful than the other (data not shown). Therefore, we have pooled the subjects irrespective of the type of behavioral treatment.

\section{Reference Children from the STOPP Study}

To be able to contrast behavioral treatment for the youngest age group with spontaneous changes, data from 36 obese (BMI-SDS > 5) children (mean age 8.5 years, range 6.4-10.3 years and BMI-SDS mean 5.8 , SD 0.9) who were followed in the STOPP study [23] for 1-3 years were evaluated. Twelve (mean age 8.5 years, range 6.5-10.2 years, BMI-SDS mean 6.2, SD 1.2) of them were followed for 3 years. In the STOPP study no intervention effect was reported among obese children and children could therefore be pooled from both the obesity prevention and the control groups.

\section{Clinically Significant Weight Loss}

Reinehr et al. [24-26] have demonstrated that a clinically significant decrease in negative health consequences for obese children is observed after a weight reduction of $\geq 0.5$ BMI-SDS units since this reduction led to improvements in cardiovascular and metabolic risk factors. Based on these observations, we specified that a clinically significant weight loss was obtained if the child had lost $\geq 0.5$ BMI-SDS units.

\section{Derivation of Patients Lost to Follow-Up}

Patients who missed follow-up visits and those who refused to show up at visits after additional contacts were classified under three main causes of loss to follow-up: i) patient's/parents' decision to stop treatment; ii) treatment goals achieved; or iii) external causes (such as patient moved, patient turned 18, no referral from a primary care physician).

\section{Statistics}

The primary statistical analyses were performed using the ANCOVA with regard to the change in BMI-SDS at follow-up years 1, 2, and 3 compared to the first visit, including BMI-SDS at the first visit as a covariate and age at start of treatment, age at onset of obesity, gender, parental weight status, SES and dropout category as fixed factors in the model. Differences among groups with respect to number of visits during the first year were analyzed using the Kruskal-Wallis test. Pair-wise comparisons were made using the Mann-Whitney test. Differences in age groups with regard to proportions of change from obesity to overweight and categorized decrease in BMI-SDS $(<0.5$ and $<1.5)$ were analyzed using the chi-square test.

Discriminate Analysis of Completers and Noncompleters

Logistic regression was used to perform an exploratory investigation of possible predictors for subjects lost to follow-up, including age, gender, BMI-SDS, parental BMI status, and parental SES as inde- 
pendent variables in the model. The odds ratio for lost to follow-up (compared to completion) was estimated for each factor.

\section{Analysis Populations}

Two analysis populations were defined: first, the complete cases (CC) population, which included all children who were completely assessed for BMI-SDS from the first visit throughout the 3-year follow-up visits; and second, the full analysis (FAS) population, which included all subjects who had a first visit. The FAS population was to be interpreted as a sensitivity analysis for the analysis with the CC population. In the FAS population, missing data for patients lost to follow-up were replaced using i) the last observation carried forward (LOCF) and ii) the baseline value carried forward (BVCF) method [3, 27].

Analyses were performed using Statistica 7.0 (Statsoft Inc., Tulsa, OK, USA). All tests used were twosided, and statistically significant results were set at $\mathrm{p}<5 \%$. All analyses are to be regarded as exploratory. No correction for multiple testing was done.

\section{Results}

A total of 555 children (272 females and 283 males) met the inclusion criteria for this study. The numbers of children in the three age groups were 125 (age 6-9 years), 263 (age 10-13 years), and 167 (age 14-16 years). The mean BMI-SDS on entering behavioral treatment (first visit) was 1.3 units higher in the 6-9 years age group than in the 10-13 years and $14-16$ years age groups $(\mathrm{p}<0.05) .81 \%$ of the children in the $6-9$ years age group were classified as obese before 3 years of age or between 3 and 6 years of age. A similar percentage of obesity (62\%) was observed in the 10-13 years age group, whereas the 14-16 years age group had a statistically significantly higher percentage (48\%) of children who had their onset of obesity after 6 years of age $(\mathrm{p}<0.05)$. The prevalence of overweight and obesity among the parents was 59\% in the fathers and 57\% in the mothers. The proportion of subjects with parents in SES 3 was 38\%. No difference in parental weight status or SES was found between age groups (table 1). The mean number of visits during the first year of treatment was 7.3 (median 3, range 1-45) for the entire group, but it varied significantly (p $=0.036$ ) among age groups. Children in the 6-9 years age group had a somewhat smaller mean number of visits $(6.2$ (median 2 , range $1-38)(\mathrm{p}<0.01)$ ), compared to children in the oldest age group with 7.8 visits (median 4 , range 1-45) and 10-13 years age group ( $p<$ $0.05)$. There was a weak correlation between the number of visits and the decrease in BMI-SDS during treatment years 1 and 2, as expected from the study design, with more frequent visits if treatment fails (see 'Material and Methods'), but no correlation was found for year 3 (data not shown).

The results for the primary analysis using the CC population and the FAS population are presented in figure 1. The mean BMI-SDS (table 2) declined from the first visit to the 3-year follow-up $(\mathrm{p}<0.05)$ and was related to age. There was a significant interaction effect between age group and time $(\mathrm{p}<0001)$. Post hoc analyses showed that the mean BMI-SDS decline was much greater for the youngest age group (6-9 years) compared to the other age groups $(\mathrm{p}=0.001)$. On adjusting for baseline differences, the mean changes in BMI-SDS from the first visit to follow-up years 1,2 , or 3 were similar with a statistically demonstrated stronger decline in the 6-9 years age group. In the 14-16 years age group the mean BMI-SDS decreased during the first year $(\mathrm{p}<0.05)$ but could not be statistically demonstrated during follow-up years 2 and 3.

Only a weak correlation was found between change in BMI-SDS from baseline to the 1-year follow-up and from baseline to the 3-year follow-up, $r=0.51(p<0.001)$ (fig. 2). Among children showing no response to treatment in the BMI-SDS, i.e., no numerical decrease, during the first year, 15 out of 18 in the 6-9 years age group, 4 out of 16 in the 10-13 years 
Table 1. Descriptive statistics of subject characteristics at baseline, i.e. mean and SD for continuous variables and frequency for categorical variables

\begin{tabular}{|c|c|c|c|c|}
\hline & $\begin{array}{l}6-9 \text { years } \\
(n=125)\end{array}$ & $\begin{array}{l}10-13 \text { years } \\
(n=263)\end{array}$ & $\begin{array}{l}\text { 14-16 years } \\
(n=167)\end{array}$ & $\begin{array}{l}\text { Total } \\
(n=555)\end{array}$ \\
\hline Mean age (SD) & $8.4(1.1)$ & $12.1(1.1)$ & $15.3(0.8)$ & \\
\hline Female/male & $64 / 61$ & $113 / 150$ & $95 / 72$ & $272 / 283$ \\
\hline \multicolumn{5}{|l|}{ Tanner score } \\
\hline 1 & $100(80 \%)$ & $71(27 \%)$ & $1(1 \%)$ & \\
\hline 2 & $5(4 \%)$ & $44(17 \%)$ & $4(2 \%)$ & \\
\hline 3 & $3(2 \%)$ & $44(17 \%)$ & $12(7 \%)$ & \\
\hline 4 & $1(1 \%)$ & $29(11 \%)$ & $30(18 \%)$ & \\
\hline 5 & 0 & $20(8 \%)$ & $71(43 \%)$ & \\
\hline Missing & $16(13 \%)$ & $55(21 \%)$ & $49(29 \%)$ & \\
\hline Mean weight, kg (min-max) & $56(28-104)$ & $82(41-155)$ & $104(66-178)$ & $82.9(28-178)$ \\
\hline $\mathrm{BMI}(\mathrm{SD})$ & $29(4.7)$ & $32(4.8)$ & $36(5.5)$ & $33(5.7)$ \\
\hline BMI-SDS (SD) & $6.7(1.7)$ & $5.4(1.3)$ & $5.2(1.2)$ & $5.7(1.5)$ \\
\hline \multicolumn{5}{|c|}{ Age at onset (iso BMI $>30$ ) of obesity } \\
\hline Before 3 years & $57(46 \%)$ & $53(20 \%)$ & $26(16 \%)$ & $136(25 \%)$ \\
\hline 3 to 6 years & $44(35 \%)$ & $110(42 \%)$ & $54(32 \%)$ & $208(37 \%)$ \\
\hline 7 years and older & $3(2 \%)$ & $42(16 \%)$ & $53(32 \%)$ & $98(18 \%)$ \\
\hline Missing & $21(17 \%)$ & $58(22 \%)$ & $34(20 \%)$ & $113(20 \%)$ \\
\hline \multicolumn{5}{|l|}{ BMI, father } \\
\hline$<25$ & $14(11 \%)$ & $50(19 \%)$ & $37(22 \%)$ & $101(18 \%)$ \\
\hline$\geq 25$ & $56(45 \%)$ & $97(37 \%)$ & $52(31 \%)$ & $205(37 \%)$ \\
\hline$\geq 30$ & $29(23 \%)$ & $61(23 \%)$ & $34(20 \%)$ & $124(22 \%)$ \\
\hline Non-reported & $26(21 \%)$ & $55(21 \%)$ & $44(26 \%)$ & $125(23 \%)$ \\
\hline \multicolumn{5}{|c|}{ Child BMI-SDS by category of father weight status } \\
\hline $\mathrm{BMI}<25$, mean $(\mathrm{SD})$ & & & & $5.4(1.4)$ \\
\hline $\mathrm{BMI} \geq 25$, mean $(\mathrm{SD})$ & & & & $5.6(1.5)$ \\
\hline $\mathrm{BMI} \geq 30$, mean $(\mathrm{SD})$ & & & & $5.9(1.6)$ \\
\hline Non-reported, mean (SD) & & & & $5.7(1.5)$ \\
\hline \multicolumn{5}{|l|}{ BMI, mother } \\
\hline$<25$ & $37(30 \%)$ & $75(29 \%)$ & $41(25 \%)$ & $153(28 \%)$ \\
\hline$\geq 25$ & $38(30 \%)$ & $71(27 \%)$ & $43(26 \%)$ & $152(27 \%)$ \\
\hline$\geq 30$ & $39(31 \%)$ & $74(28 \%)$ & $51(31 \%)$ & $164(30 \%)$ \\
\hline Non-reported & $11(9 \%)$ & $43(16 \%)$ & $32(19 \%)$ & $86(15 \%)$ \\
\hline \multicolumn{5}{|c|}{ Child BMI-SDS by category of mother weight status } \\
\hline $\mathrm{BMI}<25$, mean $(\mathrm{SD})$ & & & & $5.4(1.6)$ \\
\hline $\mathrm{BMI} \geq 25$, mean $(\mathrm{SD})$ & & & & $5.6(1.5)$ \\
\hline $\mathrm{BMI} \geq 30$, mean $(\mathrm{SD})$ & & & & $6.0(1.4)$ \\
\hline Non-reported, mean (SD) & & & & $5.5(1.4)$ \\
\hline \multicolumn{5}{|l|}{ SES } \\
\hline Academic degree & $20(16 \%)$ & $51(19 \%)$ & $31(19 \%)$ & $102(18 \%)$ \\
\hline Upper secondary education & $22(18 \%)$ & $54(21 \%)$ & $32(19 \%)$ & $108(19 \%)$ \\
\hline Others & $53(42 \%)$ & $96(37 \%)$ & $64(38 \%)$ & $213(38 \%)$ \\
\hline Non-reported & $30(24 \%)$ & $62(24 \%)$ & $38(23 \%)$ & $130(23 \%)$ \\
\hline
\end{tabular}

SES was divided into the following categories: i) at least one parent with an academic degree, ii) at least one parent r post upper secondary education and iii) others (unemployed, early/disability retired, long-term sick-listed, students, $\mathrm{m}$ ers on maternity leave). (BMI-SDS calculated according to Rolland-Cachera et al. 1982 [21]). 
Fig. 1. a BMI-SDS changes during behavioral treatment from first visit to year 3 by age group. Patients with complete, valid measurements for all three years of treatmentare presented. b BMI-SDS changes during behavioral treatment from first visit to year 3 by age group. Data for all patients with a first visit, missing values are replaced with LOCF method.

Fig. 2. Correlation between changes in BMI-SDS from baseline to 1-year follow-up (x-axis) and from baseline to 3-year follow-up (y-axis) $(\mathrm{r}=$ $0.51, \mathrm{p}<0.001$ ). As shown by prediction intervals, only limited information on the 3-year outcome can be drawn from the results of 1 year of treatment.
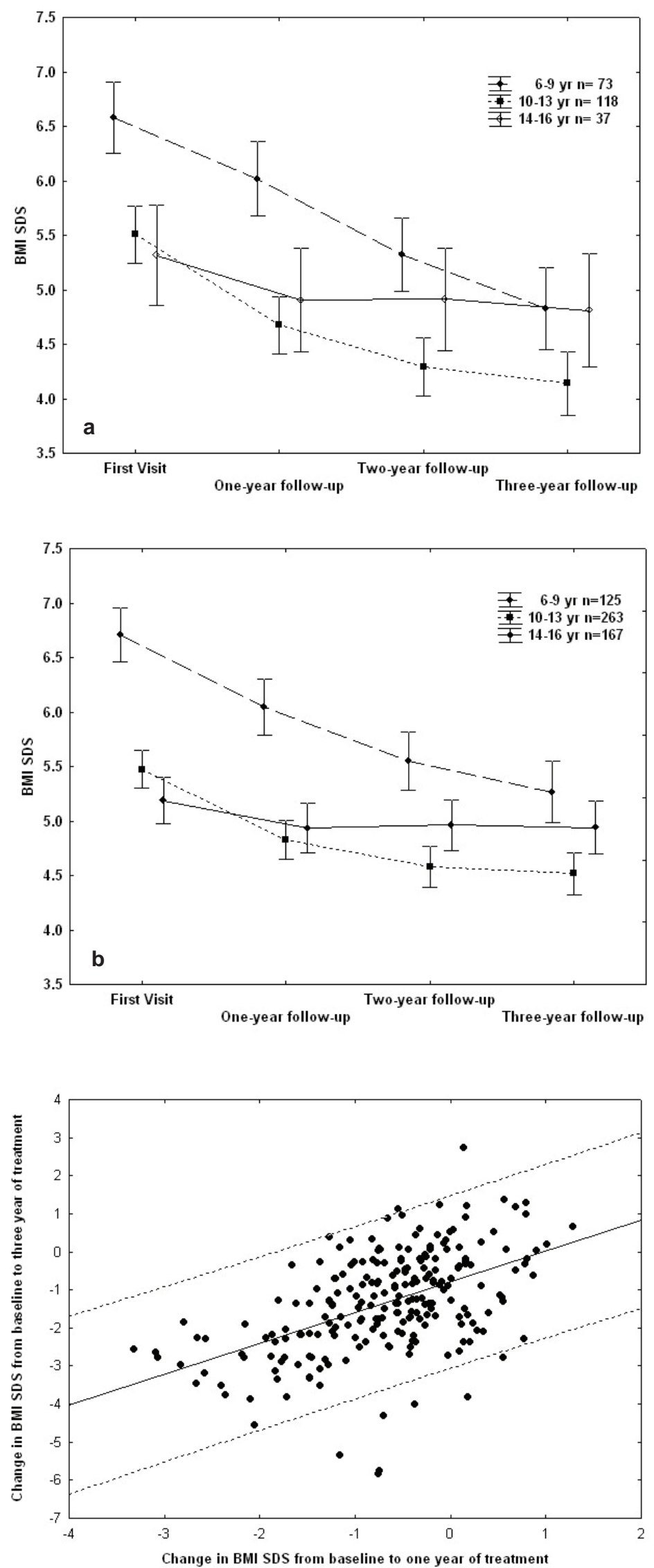
Table 2. Mean BMI-SDS for each year and age group in the CC and the two FAS populations

\begin{tabular}{|c|c|c|c|c|c|c|c|c|c|}
\hline & \multicolumn{3}{|c|}{ Completers } & \multicolumn{3}{|c|}{ FAS, LOCF } & \multicolumn{3}{|c|}{ FAS, BVCF } \\
\hline & $\begin{array}{l}\text { 6-9 years } \\
(\mathrm{n}=73)\end{array}$ & $\begin{array}{l}10-13 \\
\text { years } \\
(\mathrm{n}=118)\end{array}$ & $\begin{array}{l}14-16 \\
\text { years } \\
(\mathrm{n}=37)\end{array}$ & $\begin{array}{l}6-9 \text { years } \\
(\mathrm{n}=125)\end{array}$ & $\begin{array}{l}10-13 \\
\text { years } \\
(\mathrm{n}=263)\end{array}$ & $\begin{array}{l}\text { 14-16 year } \\
(\mathrm{n}=167)\end{array}$ & $\begin{array}{l}\text { s6-9 years } \\
(\mathrm{n}=125)\end{array}$ & $\begin{array}{l}10-13 \\
\text { years } \\
(\mathrm{n}=263)\end{array}$ & $\begin{array}{l}14-16 \\
\text { years } \\
(n=167)\end{array}$ \\
\hline First visit mean (SE) & $6.6(0.2)$ & $5.5(0.1)$ & $5.3(0.2)$ & $6.7(0.2)$ & $5.5(0.1)$ & $5.2(0.1)$ & $6.7(0.2)$ & $5.5(0.1)$ & $5.2(0.1)$ \\
\hline Year 1 mean (SE) & $6.0(0.2)$ & $4.7(0.1)$ & $4.9(0.2)$ & $6.0(0.1)$ & $4.8(0.1)$ & $4.9(0.1)$ & $6.0(0.2)$ & $4.8(0.1)$ & $4.9(0.1)$ \\
\hline Year 2 mean (SE) & $5.3(0.2)$ & $4.3(0.1)$ & $4.9(0.2)$ & $5.6(0.1)$ & $4.6(0.1)$ & $5.0(0.1)$ & $5.7(0.2)$ & $4.7(0.1)$ & $5.0(0.1)$ \\
\hline Year 3 mean (SE) & $4.8(0.2)$ & $4.2(0.2)$ & $4.8(0.3)$ & $5.3(0.1)$ & $4.5(0.1)$ & $4.9(0.1)$ & $5.7(0.2)$ & $4.9(0.1)$ & $5.1(0.1)$ \\
\hline
\end{tabular}

age group, and 3 out of 12 in the 14-16 years age group showed a clinically relevant response of at least an 0.5 unit decrease in BMI-SDS at the end of year 3.

The proportions of children with increased and decreased BMI-SDS values at follow-up visits compared to the first visit varied significantly between age groups $(\mathrm{p}<0.001)$. After 3 years, $12 \%$ of the children who started treatment at age 6-9 years showed an increased BMI-SDS and, consequently, 88\% of them showed a decreased BMI-SDS. In the 10-13 years age group the corresponding values for increased and decreased BMI-SDS were $30 \%$ and $70 \%$,respectively, and in 14-16 years age group the respective values were and $56 \%$ and $44 \%$.

After 3 years of treatment $19 \%$ of the children aged 6-9 years, $22 \%$ aged $10-13$ years, and $14 \%$ aged $14-16$ years had changed from obesity to overweight, corresponding to a BMI of less than $30 \mathrm{~kg} / \mathrm{m}^{2}$ at age 18 years. No statistically significant age group differences could be demonstrated.

There was no difference between boys and girls with regard to patterns in the mean change in BMI-SDS. Sensitivity analyses using the LOCF and BVCF methods for replacing missing data did not alter these results. Data regarding these sensitivity anlayses are presented in table 2 .

Other factors such as SES and parental BMI status did not show any statistical influence on the effect of treatment, i.e. change in BMI-SDS.

Early age at onset of obesity showed a high mean BMI-SDS at the first visit. However, no group interaction effect was found for the mean change in BMI-SDS over time across age at onset of obesity strata $(\mathrm{p}>0.05)$.

The reference group of children (age $6-10$ years, $n=12$ ) had a decrease in mean BMI-SDS of 0.46 units (SD 1.0) over a 3-year period. Reference children who were followed for only 1 year $(n=36)$ had a mean BMI-SDS change of -0.2 units (SD 0.7).

In age group 6-9 years, $24 \%$ were lost to follow-up after 3 years. Corresponding values for age groups $10-13$ and $14-16$ years were $43 \%$ and $70 \%$, respectively. The major reason for loss to follow-up was the patient's/parents' decision to stop treatment, amounting to $11 \%$ in age group 6-9 years, $29 \%$ in age group 10-13 years, and $47 \%$ in the adolescent years $14-16$. Age was thus strongly related to the risk of dropout. Patients in age groups 10-13 and 14-16 years exhibit an odds ratio for loss to follow-up of $1.79(p=0.009)$ and $5.19(p<0.001)$, respectively, compared to the 6-9 years age group, the reference group (1.0). Age at onset of obesity and gender were not statistically associated with the risk of being lost to followup.

Families with at least one parent with an academic degree showed a trend towards a lower risk (OR $=0.65, p=0.07)$ of being lost to follow-up than families with no academic 
degree. Furthermore, a trend towards an increased risk $(\mathrm{OR}=1.51, \mathrm{p}=0.09)$ of being lost to follow-up was found for children with normal-weight mothers compared to children with obese mothers. No statistically demonstrated effect of the father's weight status on the risk for being lost to follow-up was found.

\section{Discussion}

The present paper is based on a longitudinal observational study in a clinical setting and reports demographic and other patient characteristics correlated with the efficacy of continuous 3-year behavioral treatment. There are no published studies presenting more than 2 years of continuous behavioral treatment of childhood obesity [1]. Long-term followup studies of short-term interventions are helpful, but it is possible that the effects of longterm continuous treatment and long-term follow-up of short-term treatment are not comparable. It is unusual in the field of medicine to use short-term programs to treat chronic diseases, and it is also possible that a short-term treatment would not be the optimal way to treat childhood obesity.

In the present study the decline in BMI-SDS was greatest in the youngest age stratum. Furthermore, after 3 years of treatment $80 \%$ in the youngest group, 55\% in the middle group, and $28 \%$ in the adolescent group achieved a clinically significant weight loss, and $19 \%, 24 \%$ and $14 \%$, respectively, were not obese according to generally accepted criteria [20]. The decline in BMI-SDS in younger children was much more pronounced than in the obese reference group, indicating that the decline was an effect of treatment, and not a spontaneous regression towards the mean.

In a clinically based program Holm et al. [12] found the behavioral treatment to be more successful in boys. In the present study no gender differences could be detected; both boys and girls had a more pronounced decrease in BMI-SDS when treatment was initiated at 6-9 years of age than during adolescence.

It remains unclear how family characteristics may influence treatment success. The only independent factor found to be related to treatment success was age at obesity treatment onset. This is in line with previous follow-up studies of short-term behavioral treatment [3, $4,28,29]$. Age at onset of treatment was also related to the loss to follow-up. Age at onset of obesity did not affect the change in BMI-SDS during the treatment and cannot explain agedependent differences in treatment effects. SES and parental weight status did not significantly predict either the risk of being lost to follow-up or the treatment effect. The lack of association between SES and treatment effect has also been found in British children [28]. This is surprising since it has been well established that the prevalence of overweight and obesity is higher among children in low socioeconomic strata in industrialized countries [30], and we observed in the same cohort an association between degree of obesity and SES [31].

The present study also indicates that the 1-year treatment outcome only weakly reflects the long-term effect. $84 \%$ of the children and adolescents who were non-responders during the first year of treatment had a clinically significant weight loss after 3 years. Previous follow-up studies have shown that the result after 1 year of treatment predicts the long-term outcome [29]. Thus, despite the fact that the initial effect of short-term treatment can be observed after a long observation time, the predictive value of 1 year of treatment on the effect of long-term continuous treatment is weak. This indicates that termination of treatment if no initial effect on weight is obtained is probably wrong, especially considering that it has been demonstrated that the initiation of obesity treatment may be associated with reduced self-esteem [32]. A general problem in obesity treatment is the high rate of dropouts. This was also found in the present study, especially in the adolescent group with 
only $30 \%$ of the subjects remaining after 3 years. However, the retention rate was higher compared to a previous study on clinical practice [3] where only $8 \%$ remained after 24 months of treatment. Generally speaking, treatment durations appear to be associated with the degree of dropouts, with lower rates in short-term treatment [4, 29]. From a cost-benefit point of view it can be questioned whether treatment results and dropout rates found in the adolescent group are acceptable. However, since we have no possibilities at present to identify dropout and non-responder individuals, it is still ethically justified to offer adolescents behavioral obesity treatment. On the other hand it is urgent both to improve the treatment methods and to identify adolescents at risk of dropping out. Previously, Denzer et al. [9] and Barlow et al. [10] have reported that the degree of obesity at treatment onset was the only factor of importance for retention rate, whereas Zeller et al. [11] and Holm et al. [12] found the age at start of treatment to be the dependent factor for not dropping out. Except for age at treatment onset, we were not able to define any high-risk subgroups. After conducting LOCF and observed cases procedures, we found no associations between dropout and degree of obesity or effect of treatment before dropping out.

We presented sensitivity analyses on two various analysis populations: LOCF and BVCF . Although LOCF is normally regarded as a conservative method for replacing missing data, in obese children this method may underestimate the levels of BMI-SDS since they may increase over time. Therefore, we also used BVCF as an even more conservative method for replacing missing data, although it probably overestimates BMI-SDS over time. However, the results in the present study were the same for completers in LOCF and BVCF populations.

There was a trend towards a higher risk of dropout among children with normal-weight mothers, although Jelalian et al. [33] reported contradictory results where a high parental BMI increased the risk of adolescents dropping out of treatment in a 16-week behavioral intervention. The risk of dropping out did not differ between SES strata. The SES effect on dropping out appears to be complex. Higher dropout rates have been reported in both lower and higher SES strata $[7,11]$.

\section{Strengths and Limitations}

The present study is strengthened by the relatively large sample size and long treatment duration. A major limitation is the lack of untreated randomized age-matched control groups. However, we found it practically and ethically impossible to maintain an untreated control group for several years. Furthermore, the aim of the study was not to find the optimal form of behavioral treatment but to identify factors of general importance for behavioral treatment success. We regard the more pronounced decline in BMI-SDS in the youngest age group as an effect of treatment. This is supported by the very modest decline in 6- to 8 -year-old controls and recent studies showing that from 6 to 7 years of age obesity and overweight have a poor prognosis [34-36]. In addition, our observations regarding the poor correlation between the results of 1 year of treatment and 3 years of continuous treatment, the association between the lost to follow-up and age at start of treatment and, finally, the lack of correlation between SES and outcome are all independent of control groups. We have chosen to use the Rolland Cachera method [21] for calculation of BMI-SDS values. This method and other $[21,37,38]$ may all be biased to skewness in the reference population wherefrom the criteria for calculations of BMI-SDS are defined. Extreme individual values of BMI-SDS tend to be underestimated the more skewed data is in the reference population.

A limitation of the study is the high dropout/loss to follow-up rate which may strongly influence the interpretation of the results, especially in the adolescent group. However, this paper reports data from a clinical practice without incentives for the families to remain in the study and reflects the general situation for behavioral obesity treatment. The lack of reliable ethnicity data constitutes another limitation of the study. 


\section{Conclusion}

It is possible to treat severely obese children with behavioral therapy with acceptable long-term results if the treatment is initiated at an early age. Identifying obese children and initiating early treatment may reduce the number of severely obese adolescents in need of pharmaceutical or surgical treatment. Future research should be focused on ways to identify patients at risk of dropping out of treatment and to develop new strategies to reduce the dropout rate.

\section{Acknowledgements}

This study was funded by the Swedish Association of Local Authorities and Regions and the Swedish National Board of Health and Welfare, the Stockholm Free Masons Foundation for Children's Welfare, the Department of Clinical Science, Intervention and Technology (CLINTEC), Karolinska Institutet, the Wera Ekström Foundation, and the Samariten Foundation. Clinical Trial Identifier NCT 01029964.

\section{Disclosure Statement}

The authors have no conflict of interest to declare.

\section{References}

1 Luttikhuis HO, Baur L, Jansen H, Shrewsbury VA, O’Malley C, Stolk RP, Summerbell CD: Interventions for treating obesity in children. Cochrane Database Syst Rev 2009:CD001872.

2 Epstein LH, Valoski A, Wing RR, McCurley J: 10-year outcomes of behavioral family-based treatment for childhood obesity. Health Psychol 1994;13:373-383.

3 Reinehr T, Widhalm K, L'Allemand D, Wiegand S, Wabitsch M, Holl RW: Two-year follow-up in 21,784 overweight children and adolescents with lifestyle intervention. Obesity (Silver Spring) 2009;17:1196-1199.

- 4 Reinehr T, Kleber M, Lass N, Toschke AM: Body mass index patterns over 5 y in obese children motivated to participate in a 1-y lifestyle intervention: Age as a predictor of long-term success. Am J Clin Nutr 2010; 91:1165-1171.

5 Danielzik S, Czerwinski-Mast M, Langnase K, Dilba B, Müller MJ: Parental overweight, socioeconomic status and high birth weight are the major determinants of overweight and obesity in 5-7 y-old children: Baseline data of the Kiel Obesity Prevention Study (KOPS). Int J Obes 2004;28:1494-1502.

- 6 Pinelli L, Elerdini N, Faith MS, Agnello D, Ambruzzi A, De Simone M, Leggeri G, Livieri C, Monetti N, Peverelli P, Salvatoni A, Seminara S, Uasone R, Pietrobelli A: Childhood obesity: results of a multicenter study of obesity treatment in Italy. J Pediatr Endocrinol Metab 1999;12(suppl 3):795-799.

7 Inelmen EM, Toffanello ED, Enzi G, Gasparini G, Miotto F, Sergi G, Busetto L: Predictors of drop-out in overweight and obese outpatients. Int J Obes 2005;29:122-128.

$\checkmark 8$ Melin I, Reynisdottir S, Berglund L, Zamfir M, Karlstrom B: Conservative treatment of obesity in an academic obesity unit. Long-term outcome and drop-out. Eat Weight Disord 2006;11:22-30.

- 9 Denzer C, Reithofer E, Wabitsch M, Widhalm K: The outcome of childhood obesity management depends highly upon patient compliance. Eur J Pediatr 2004;163:99-104.

10 Barlow SE, Ohlemeyer CL: Parent reasons for nonreturn to a pediatric weight management program. Clin Pediatr 2006;45:355-360.

11 Zeller M, Kirk S, Claytor R, Khoury P, Grieme J, Santangelo M, Daniels S: Predictors of attrition from a pediatric weight management program. J Pediatr 2004;144:466-470.

$\checkmark 12$ Holm JC, Gamborg M, Bille DS, Gronbaek HN, Ward LC, Faerk J: Chronic care treatment of obese children and adolescents. Int J Pediatr Obes 2011;6:188-196.

13 Danielsson P, Janson A, Norgren S, Marcus C: Impact sibutramine therapy in children with hypothalamic obesity or obesity with aggravating syndromes. J Clin Endocrinol Metab 2007;92:4101-4106.

14 Norgren S, Danielsson P, Jurold R, Lotborn M, Marcus C: Orlistat treatment in obese prepubertal children: a pilot study. Acta Paediatrica 2003;92:666-670.

15 Kamel A, Norgren S, Elimam A, Danielsson P, Marcus C: Effects of growth hormone treatment in obese prepubertal boys. J Clin Endocrinol Metab 2000;85:1412-1419. 
-16 Baker JL, Farpour-Lambert NJ, Nowicka P, Pietrobelli A, Weiss R: Evaluation of the overweight/obese child - practical tips for the primary health care provider: recommendations from the Childhood Obesity Task Force of the European Association for the Study of Obesity. Obes Facts 2010;3:131-137.

$\checkmark 17$ Barlow SE: Expert committee recommendations regarding the prevention, assessment, and treatment of child and adolescent overweight and obesity: summary report. Pediatrics 2007;120:S164-S192.

-18 Krebs NF, Himes JH, Jacobson D, Nicklas TA, Guilday P, Styne D: Assessment of child and adolescent overweight and obesity. Pediatrics 2007;120:S193-S228.

-19 Spear BA, Barlow SE, Ervin C, Ludwig DS, Saelens BE, Schetzina KE, Taveras EM: Recommendations for treatment of child and adolescent overweight and obesity. Pediatrics 2007;120:S254-S288.

-20 Cole TJ, Bellizzi MC, Flegal KM, Dietz WH: Establishing a standard definition for child overweight and obesity worldwide: International survey. Br Med J 2000;320:1240-1243.

-21 Rolland Cachera MF, Sempe M, Guilloudbataille M, Patois E, Pequignot-Guggenbuhl F, Fautrad V: Adiposity indexes in children. Am J Clin Nutr 1982;36:178-184.

22 WHO: Preventing and Managing the Global Epidemic of Obesity. Report of the World Health Organization Consultation of Obesity. Geneva, WHO, 1997

-23 Marcus C, Nyberg G, Nordenfelt A, Karpmyr M, Kowalski J, Ekelund U: A 4-year, cluster-randomized, controlled childhood obesity prevention study: Stopp. Int J Obes 2009;33:408-417.

24 Reinehr T, Andler W: Changes in the atherogenic risk factor profile according to degree of weight loss. Arch Dis Child 2004;89:419-422.

-25 Reinehr T, Kiess W, Kapellen T, Andler W: Insulin sensitivity among obese children and adolescents, according to degree of weight loss. Pediatrics 2004;114:1569-1573.

26 Reinehr T, Kleber M, Toschke AM: Lifestyle intervention in obese children is associated with a decrease of the metabolic syndrome prevalence. Atherosclerosis 2009;207:174-180.

-27 Reinehr T, Temmesfeld M, Kersting M, De Sousa G, Toschke AM: Four-year follow-up of children and adolescents participating in an obesity intervention program. Int J Obesity 2007;31:1074-1077.

28 Sabin MA, Ford A, Hunt L, Jamal R, Crowne EC, Shield JPH: Which factors are associated with a successful outcome in a weight management programme for obese children? J Eval Clin Pract 2007;13:364-368.

-29 Reinehr T, Hoffmeister U, Mann R, Goldapp C, Westenhofer J, Egmond-Froehlich A, Bullinger M, RavensSieberer U, Holl RW: Medical care of overweight children under real-life conditions: The german bzga observation study. Int J Obes 2009;33:418-423.

-30 Lobstein T BLaUR: Obesity in children and young people: A crises in public health. Obes Rev 2004;5:4-85.

-31 Svensson V, Jacobsson JA, Fredriksson R, Danielsson P, Sobko T, Schioth HB, Marcus C: Associations between severity of obesity in childhood and adolescence, obesity onset and parental BMI: a longitudinal cohort study. Int J Obes 2011;35:46-52.

-32 Cameron JW: Self-esteem changes in children enrolled in weight management programs. Issues Compr Pediatr Nurs 1999;22:75-85.

-33 Jelalian E, Hart CN, Mehlenbeck RS, Lloyd-Richardson EE, Kaplan JD, Flynn-O’Brien KT, Wing RR: Predictors of attrition and weight loss in an adolescent weight control program. Obesity 2008;16:1318-1323.

34 Timpka T, Angbratt M, Bolme P, Hermansson G, Hager A, Valter L: A high-precision protocol for identification of preschool children at risk for persisting obesity. PloS One 2007;2:e535.

-35 Gardner DSL, Hosking J, Metcalf BS, Jeffery AN, Voss LD, Wilkin TJ: Contribution of early weight gain to childhood overweight and metabolic health: a longitudinal study (earlybird 36). Pediatrics 2009;123:E67E73.

-36 Nader PR, O’Brien M, Houts R, Bradley R, Belsky J, Crosnoe R, Friedman S, Mei ZG, Susman EJ: Identifying risk for obesity in early childhood. Pediatrics 2006;118:E594-E601.

-37 Karlberg J, Luo ZC, Albertsson-Wikland K: Body mass index reference values (mean and sd) for Swedish children. Acta Paediatrica 2001;90:1427-1434.

-38 Cole TJ: The lms method for constructing normalized growth standards. Eur J Clin Nutr 1990;44:45-60. 